\title{
Vascular endothelial growth factor blockade rapidly elicits alternative proangiogenic pathways in neuroblastoma
}

\author{
NIBAL ZAGHLOUL ${ }^{1,4}$, SONIA L. HERNANDEZ ${ }^{1}$, JAE-O BAE ${ }^{2}$, JIANZHONG HUANG ${ }^{2}$, JASON C. FISHER ${ }^{2}$, \\ ALICE LEE $^{1}$, ANGELA KADENHE-CHIWESHE ${ }^{2}$, JESSICA J. KANDEL ${ }^{*}$ and DARRELL J. YAMASHIRO ${ }^{1-3 *}$ \\ Departments of ${ }^{1}$ Pediatrics, ${ }^{2}$ Surgery, ${ }^{3}$ Pathology, College of Physicians and \\ Surgeons of Columbia University, 630 West 168th Street, New York, NY 10032, USA
}

Received August 21, 2008; Accepted October 27, 2008

DOI: 10.3892/ijo_00000163

\begin{abstract}
Most children with neuroblastoma presenting after infancy have metastatic, chemoresistant disease. Amplification of the MYCN proto-oncogene is a significant marker of these poor-prognosis neuroblastoma tumors. Recent studies suggest that $M Y C N$ may function in part by promoting angiogenesis via vascular endothelial growth factor (VEGF). VEGF blockade has been validated as a therapeutic strategy in adult cancers. In these studies, we asked whether inhibition of VEGF signaling via VEGFR2 blockade in established $M Y C N$ amplified neuroblastoma xenografts would: 1) restrict tumor growth; 2) induce hypoxia; and 3) alter tumor vasculature. The $M Y C N$-amplified neuroblastoma human cell line NGP was implanted intrarenally in athymic female mice. After 5 weeks, mice with established tumors were selected, a cohort euthanized to provide day 0 controls, and the rest assigned to receive biweekly injections of DC101 (anti-murine VEGFR2 antibody) or vehicle. DC101 treatment did not inhibit progressive tumor growth in established NGP xenografts. Although tumor vasculature was not significantly disrupted, a modest increase in tumor hypoxia was demonstrated by pimonidazole staining, and expression of a previously described hypoxia metagene was increased by gene set enrichment analysis (GSEA) in DC101-treated tumors. DC101 treatment elicited increased: 1) expression of VEGFR1 and its ligand placental growth factor; and 2) increased Notch activation in tumor vasculature concurrent with expression of the Notch
\end{abstract}

Correspondence to: Dr Darrell J. Yamashiro, Pediatric Oncology, Irving Cancer Research Center, 1130 St. Nicholas Ave, Room 924A, New York, NY 10032, USA

E-mail: dy39@columbia.edu

Present address: ${ }^{4}$ Akron Children's Center for Blood and Cancer, 1044 Belmont Ave, Youngstown, OH 44501, USA

${ }^{*}$ Contributed equally

Key words: angiogenesis, neuroblastoma, Notch, placental growth factor, vascular endothelial growth factor ligand Jagged1. This result suggests that established $M Y C N$ amplified neuroblastoma tumors are relatively VEGFindependent, and display the ability to rapidly up-regulate hypoxia-responsive alternative proangiogenic mechanisms that may stabilize vasculature when VEGF is deficient.

\section{Introduction}

Despite intensification of chemotherapy and the use of bone marrow transplantation, few children with metastatic neuroblastoma currently survive. As in other human cancers (1-5), expression of VEGF and other proangiogenic factors has been associated with poor outcome in clinical neuroblastoma (6). Considerable data indicate that VEGF exerts its major effects on tumor angiogenesis via its VEGFR2 receptor, although VEGF also binds to VEGFR1 and the non-kinase receptor neuropilin-1 (7-9).

The development of a variety of agents which bind VEGF or block its signaling via VEGFR2 has resulted in a body of research demonstrating that interruption of this signaling axis is broadly effective in inhibiting pathologic angiogenesis. The accumulating clinical experience with anti-VEGF agents has borne out these experimental findings, yet has equally clearly presented new problems: certain tumors respond only minimally, to VEGF inhibitors, and even those whose cancers respond will virtually all ultimately progress (10-12). The mechanisms of tumor resistance to VEGF blockade are not known.

Previous studies in mouse models and humans suggest that VEGF/VEGFR2 blockade can elicit expression of other proangiogenic growth factors that may function to increase vascular survival, and thus rescue tumor blood supply (13-16). Such mechanisms may be important in governing both the initial tumor response and the development of resistance to inhibition of VEGF signaling. Activation of VEGFR1 is one such candidate pathway. VEGFR1 is principally expressed in endothelial cells (ECs) and in certain pericytes (17-19). Signaling is triggered by multiple ligands, including VEGF itself and the VEGFR1-selective ligand placental growth factor (PlGF). The importance of PIGF/VEGFR1 signaling is suggested by the observation that both VEGFR1-kinase null and PlGF-null mice display defects in pathologic and tumor angiogenesis $(20,21)$. PIGF expression is a marker for poor 
prognosis in breast, renal, and other cancers (22-25), and up-regulation of PIGF was found after treatment with the antiVEGF antibody bevacizumab in both rectal cancer patients (16) and xenograft-bearing mice (26). Thus, these data support the concept that PlGF/VEGFR1 signaling may play a role in the response to VEGF blockade.

The more recently characterized Notch family includes four receptors (Notch1 through Notch4), and five transmembrane ligands (Jagged 1, 2, and Delta-like 1, 3, 4). While Notch proteins are broadly implicated in cell fate determination, they are directly responsible for normal vascular development. Notch signaling is also implicated in tumor angiogenesis. For example, $\gamma$-secretase inhibitors (27) prevent processing of the Notch receptor after ligand binding, and repress formation of tumor neovascular networks. In addition, the Notch ligand Jagged1 is a tumor prognostic marker that contributes to vascular integrity. Tumor cells engineered to overexpress Jagged1 can interact with endothelia to directly promote angiogenesis (28). The mechanisms by which Jagged1 signaling supports tumor vasculature are not completely understood, but are likely to involve stabilizing interactions between ECs and adjacent cells. In support of this concept, mice lacking Jagged1 display defective vascular assembly and hemorrhage (29). Further, expression of Jagged1 increases in EC and vascular mural cells (VMC) in an arterial injury model (30). Taken together, these data suggest that Jagged1 may function to protect vasculature by stimulating Notch signaling, and that this mechanism may be elicited by microenvironmental stress.

Recent clinical experience has validated the choice of VEGF as a target for cancer therapy. However, the differential susceptibility of certain neoplasms has stimulated interest in alternative mechanisms that may rescue tumor perfusion. In these studies, we demonstrated that $M Y C N$-amplified experimental neuroblastoma tumors are relatively resistant to VEGFR2 inhibition, and display increased activity of two pathways likely to support vascular survival (PIGF/VEGFR1 and Jagged1/Notch). Thus, the present study may provide important information to guide the development of antiangiogenic strategies in this childhood cancer.

\section{Materials and methods}

Cell line. NGP-GFP, MYCN-amplified human neuroblastoma cell lines transfected with retroviral vector containing green fluorescent protein, were cultured and maintained in $75-\mathrm{cm}^{2}$ flasks using RPMI-1640 supplemented with $10 \%$ fetal bovine serum and $1 \%$ penicillin-streptomycin. Cells were cultured to confluence at $37^{\circ} \mathrm{C}$ in $5 \% \mathrm{CO}_{2}$, harvested with versene, and counted. They were then washed and resuspended in sterile PBS at $10^{7}$ cells $/ \mathrm{ml}$, and kept on ice prior to implantation into mice.

Tumor implantation. The experiment was approved by the Institutional Animal Care and Use Committee of Columbia University. Four- to six-week-old female NCR nude mice (NCI Frederick) were housed in a barrier facility and acclaimed to 12-h light-dark cycles for at least a day before use. The mice were anesthetized, and the left flank was prepared sterilely. An incision was made to expose the left kidney, and an inoculum of $10^{6}$ tumor cells $(0.1 \mathrm{ml})$ injected using a 25 -gauge needle. The flank muscles were then closed with absorbable suture, and skin closed with staples.

Administration of DC101 and placebo. After 5 weeks, mice with established xenografts were selected. An initial cohort $(\mathrm{N}=10)$ were euthanized to provide day 0 controls, and the remaining animals randomly divided into 2 groups: a control group receiving sterile PBS (control group), and a treatment group receiving DC101 (anti-murine VEGFR2 blocking antibody, Imclone). Animals received biweekly injection of $0.2 \mathrm{ml} / \mathrm{mouse}$ of sterile PBS (controls) or $860 \mu \mathrm{g} \mathrm{DC} 101$ (treatment group). The cohorts were monitored for tumor progression, and euthanized at day 10 of treatment.

Tumor processing. Hydroxyprobe $(60 \mathrm{mg} / \mathrm{kg}$ ) (pimonidazole; Chemicon, \#9020) was injected intraperitoneally $45 \mathrm{~min}$ prior to euthanasia. Tumors were harvested after perfusion via the left ventricle with fluorescein-labeled Lycopersicon esculentum lectin, and vessel then fixed with $1 \%$ paraformaldehyde infusion ( $\mathrm{pH} 7.4$, diluted in PBS) followed by washing with PBS. Tissues were preserved using $4 \%$ paraformaldehyde overnight followed by serial dehydration with ethanol in DEPC-treated water, and embedded in paraffin for immunohistochemistry. Tissue for protein studies was snap-frozen in liquid nitrogen, and stored at $-80^{\circ} \mathrm{C}$. Tissue was fresh-frozen by placing parts of the tumors in micro-cassettes, embedding with OCT compound (Sakura, CA, USA), immersing in methylbutane with dry ice, then stored in $-80^{\circ} \mathrm{C}$.

Immunohistochemistry. Tissue sections $(5 \mu \mathrm{m})$ were cut from paraffin blocks and used for the following immunostains: 1) PECAM-1 (platelet-endothelial cell adhesion molecule-1) a marker specific for endothelial cells (RDI-MCD31abrt, Research Diagnostics), diluted 1:50;2) aSMA ( $\alpha$-smooth muscle actin; NeoMakers, \#RB-9010-P1), diluted 1:100; 3) Collagen IV (CosmoBio, \#LB-1403) diluted 1:1000; 4) hypoxyprobe (pimonidazole) detected by using Hypoxyprobe Mab-1 (Chemicon kit, \#90204) diluted in 1:50; 5) VEGFR1 (AF471, R\&D Systems), diluted 1:100; 6) Jagged1 (AF1277, R\&D Systems), diluted 1:100; D114 (AF1389, R\&D Systems), diluted 1:50. Sections were first baked, deparaffinized in xylene, and rehydrated. Endogenous peroxidase was quenched in 3\% hydrogen peroxide (Sigma) for $20 \mathrm{~min}$. Slides were developed by applying HRP-Streptavidin Plus following secondary antibody application. Slides were examined with a Nikon Eclipse E600 microscope. Quantification of vascular density by aSMA was performed as previously described (15).

Fluorescent immunohistochemistry. Immunofluorescence was performed on frozen specimens. Sections $(5 \mu \mathrm{m})$ were cut from tumors embedded in OCT and stored at $-80^{\circ} \mathrm{C}$. Slides were brought to room temperature, washed in ice-cold acetone for $10 \mathrm{~min}$, incubated with avidin/biotin. Primary antibodies utilized were: 1) Phosphorylated VEGFR1 using phosphospecific anti-VEGFR1 antibody (07-758, Millipore), diluted 1:500; 2) Notch1 (05-557, Upstate), diluted 1:10; 3) cleaved Notch1 (2421, Cell Signaling), diluted 1:50. A biotinylated secondary antibody was used in combination with fluorophorelabeled avidin to visualize signals. Slides were examined 


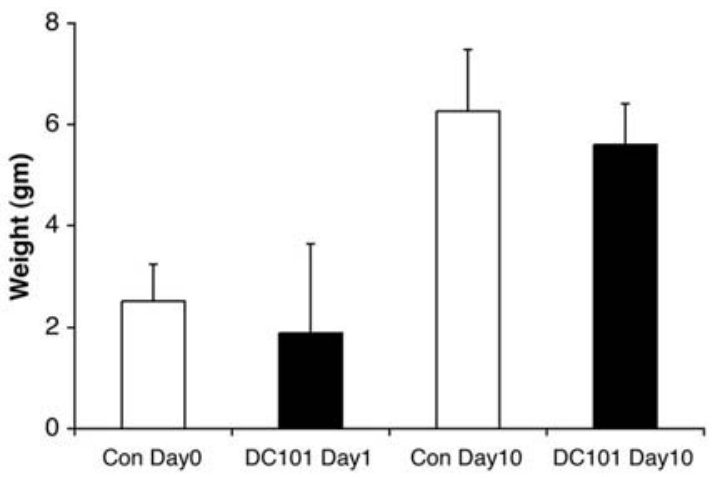

Figure 1. VEGFR2 blockade by DC101 antibody did not restrict growth of NGP tumors. At day 10, mean weight of DC101-treated tumors was $6.3 \pm 1.2 \mathrm{~g}$, as compared to $5.6 \pm 0.8 \mathrm{~g}$ for untreated controls ( $\mathrm{P}=\mathrm{NS}$ ).

with a Nikon Eclipse E600 microscope and photographed by fluorescent microscopy.

Microarray studies and gene set expression analysis. To conduct microarray analysis, high-density oligonucleotide microarray GeneChips (HGU133A, Affymetrix, CA) were used to analyze expression profiles of xenograft tumors. In brief, total RNA extracted from tumor tissues was tworounds linearly amplified (RiboAmp RNA amplification kit, Arcturus, CA) and converted to cDNA, hybridized to chips, and scanned at the Columbia University Core Genomics facility. Gene set expression analysis (GSEA) was performed on microarray data according to the procedure reported and software provided by Subramanian et al (31), and using the hypoxia metagene described by Winter and coworkers (32).

Statistical significance was calculated to compare tumor sizes and relative PlGF expression by Kruskal-Wallis analysis, utilizing Analyse-It + Excel statistical software.

PlGF ELISA. Tumors stored at $-80^{\circ} \mathrm{C}$ were weighed and lysis buffer added in a ratio of $100 \mu \mathrm{l}$ of lysis buffer to $10 \mathrm{mg}$ of tumor. Tissues were homogenized on ice using a Polytron tissue disrupter, and centrifuged at $10,000 \mathrm{rpm}$ for $10 \mathrm{~min}$ at $4^{\circ} \mathrm{C}$. Protein samples were aliquoted, frozen at $-20^{\circ} \mathrm{C}$ until the assay was performed. PMSF ( $1 \mathrm{mM}$ final concentration) and protease inhibitor cocktail (\#1271700, Roche) were added right before homogenizing. Protein concentrations were determined using the Lowry assay (Biorad) on a 96-well plate reader, following the manufacturer's instructions. PlGF was quantified by ELISA, following the manufacturer's instructions (PDG00, R\&D Systems).

\section{Results}

NGP tumors are not suppressed by VEGFR2 blockade, and tumor vasculature is minimally disrupted. We examined the role of VEGFR2 in NGP utilizing DC101, a murine specific anti-VEGFR2 antibody (33). Treatment of NGP xenografts with DC101 did not restrict growth of NGP tumors (Fig. 1, day 10: $6.3+1.2 \mathrm{~g}$ vs. $5.6 \pm 0.8 \mathrm{~g}$, controls vs. DC101-treated respectively; $\mathrm{p}=\mathrm{NS}$ ). DC101-treated NGP xenograft vessel networks were neither pruned of small branches nor remodeled (Fig. 2), with unchanged vascular density as quantified from

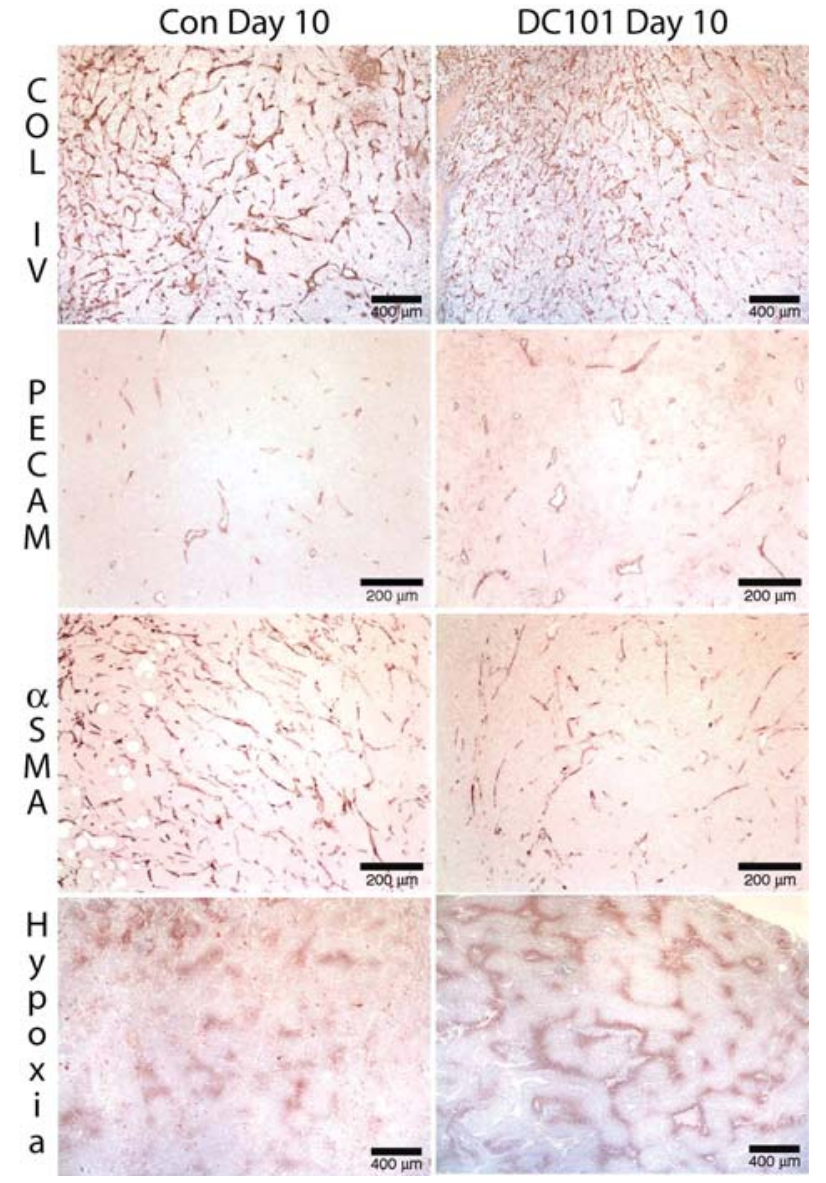

Figure 2. Treatment of NGP xenografts with DC101 minimally perturbs NGP tumor angiogenesis. Vasculature is largely preserved in NGP tumors after DC101 treatment, with little change in vascular basement membrane (COL IV), endothelial cells (PECAM), or vascular mural cell patterns ( $\alpha$ SMA). However, a modest increase in pimonidazole straining is evident (Hypoxia), indicative of hypoxic regions.

aSMA immunohistochemistry (mean vascular density in day 10, DC101-treated xenografts $101 \%$ of control as calculated by computer-assisted image analysis).

VEGFR2 inhibition increases tumor hypoxia in NGP xenografts. Subtle effects of VEGFR2 blockade on both perfusion and tumors were suggested by a modest increase in tumor hypoxia, shown by pimonidazole staining (Fig. 2, bottom panel). This finding suggests that while NGP tumor vasculature is minimally disrupted by blockade of VEGFR2, subtle evidence of disrupted perfusion may be present.

VEGFR2 blockade elicits compensatory hypoxia-regulated pathways in NGP tumors. To determine if hypoxia related gene expression profiles might be altered by this treatment, we examined alterations in a 'hypoxia metagene', described by Winter et al (32). This gene set significantly distinguishes clinically aggressive subsets of biologically distinct human tumors (e.g. head and neck, breast cancer). The metagene includes genes implicated in angiogenesis (e.g. VEGF, PlGF), glucose metabolism (e.g. PGK), hypoxia-induced apoptosis (e.g. BNIP3), and Notch activation (HEY2) suggesting that these contribute to therapy-resistant cancer phenotypes. To 
A

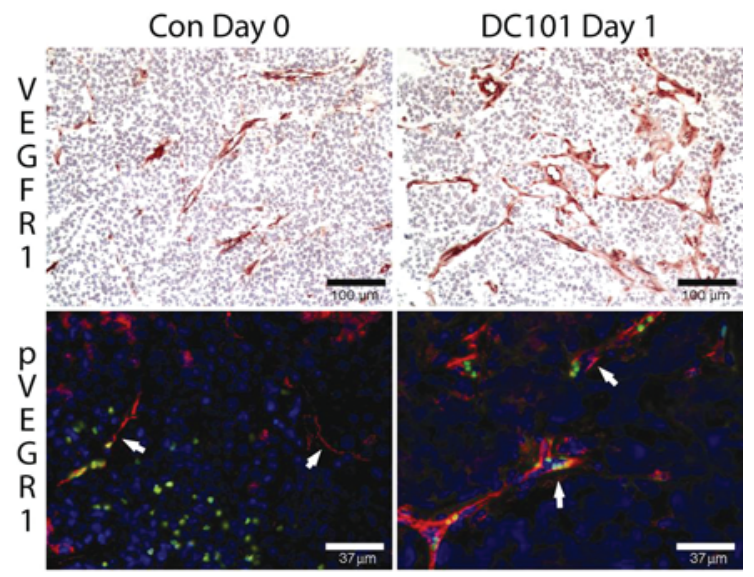

B

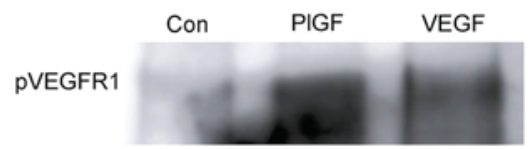

\section{C}

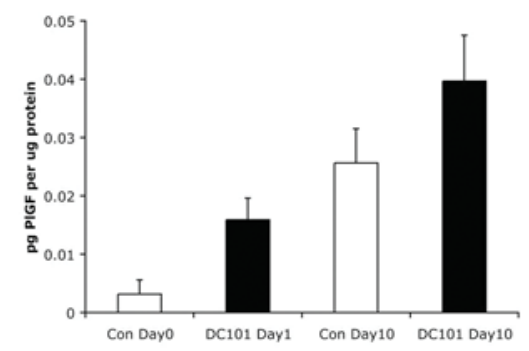

Figure 3. VEGFR1 is expressed in NGP, and activation increases during inhibition of VEGFR2. The presence of VEGFR1 in untreated NGP tumor vasculature suggested that this pathway might be involved in the relative VEGFR2-independence of NGP xenografts. (A) VEGFR1 increased in NGP tumor vessels during DC101 treatment. The phosphorylated form of this receptor (pVEGFR1) was present in control tumors, and also increased during inhibition of VEGFR2. (B) Specificity of the anti-pVEGFR1 antibody was confirmed by Western blot analysis in serum-starved HUVECs treated with PIGF or VEGF. (C) PlGF expression, a VEGFR1 selective ligand, significantly increased in treated but not control NGP tumors between day 1 and 10 by ELISA $(0.015 \mathrm{pg} / \mathrm{mg}$ protein day 1 versus $0.040 \mathrm{pg} / \mathrm{mg}$ protein day 10 DC101-treated tumors, $\mathrm{p}<0.04)$, and localized by immunohistochemistry (data not shown).

examine the possibility that such pathways were involved in the responses of NGP to DC101, we compared microarray data from control and DC101-treated tumors using this metagene (217 identifiers) and gene set enrichment analysis (GSEA) (31). Metagene expression was significantly enriched in DC101-treated NGP (nominal $\mathrm{p}<0.0001$, family-wise error rate $<0.0001$ ). Leading-edge genes (those elements which contribute most to the statistic) included VEGF and the downstream Notch target gene HEY2. These data are consistent with the increase in hypoxia that we detected by IHC, and suggest that NGP responds to VEGFR2 blockade by activating multiple pathways, including angiogenesis and Notch-related cascades.

VEGFR1 is expressed in NGP, and phosphorylation ( $p V E G F R 1)$ increases during VEGFR2 inhibition. The
A

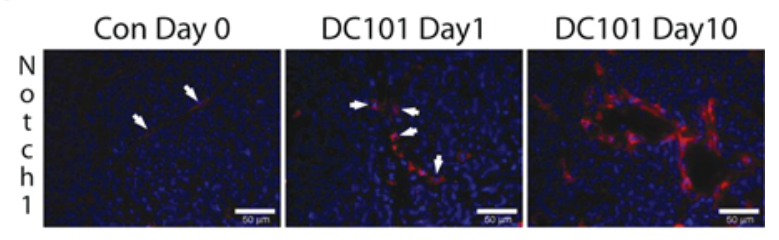

B

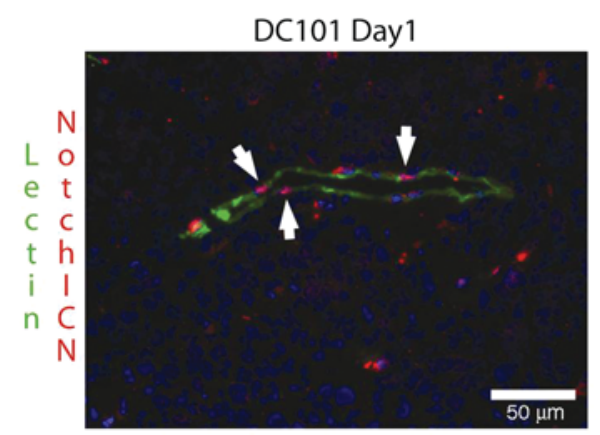

C

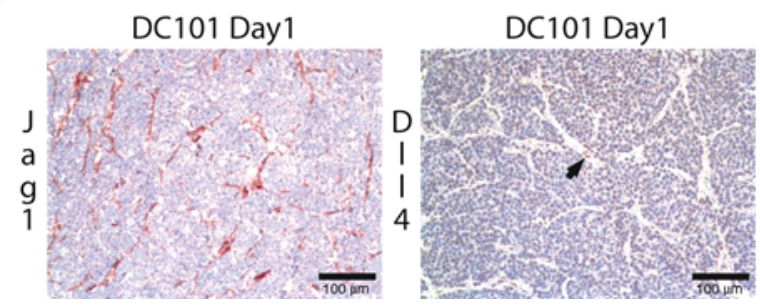

Figure 4. The Notch pathway is activated in vasculature of DC101-treated NGP tumors, and vessels express the Notch ligand Jagged1. We examined expression of Notch receptors and ligands in DC101-treated NGP xenografts. (A) Notch1 is readily detected in the vasculature of control day 0 tumors, and increased 1 day after initiation of VEGFR2 blockade, persisting at day 10. (B) Activated Notch was detected using an antibody to the cytoplasmic peptide (Notch ICN) released when receptor/ligand binding occurs. Notch ICN expression increased in vasculature of DC101-treated tumors, but was rarely detectable in control tumors (not shown). (C) The Notch ligand Jagged1, previously shown to stabilize endothelial cells via contacts with perivascular cells, was also highly expressed in vasculature of NGP controls, and persisted after DC101 treatment, whereas the Notch ligand D114 was rarely expressed in NGP control and DC101-treated tumors.

presence of the VEGFR1/P1GF pathway in recurrent vasculature of SY5Y suggested the possibility that this axis might be involved in the relative VEGFR2-independence of NGP xenografts. Indeed, NGP control tumor vasculature was broadly VEGFR1-immuno-positive, which increased during DC101 treatment (Fig. 3A). pVEGFR1 was detected in control tumors, and increased with DC101 (Fig. 3A). Specificity of the anti-pVEGFR1 antibody was confirmed by Western blot analysis in serum-starved human umbilical vein endothelial cells (HUVECs) treated with PIGF or VEGF (Fig. 3B). PIGF protein, a VEGFR1 selective ligand, significantly increased in treated but not control NGP tumors between day 1 and 10 by ELISA $(0.015 \mathrm{pg} / \mathrm{mg}$ protein day 1 versus $0.040 \mathrm{pg} / \mathrm{mg}$ protein day 10 DC101-treated tumors, p<0.04, Fig. 3C), and localized by immunohistochemistry (data not shown). These findings indicate that this ligand, in addition to VEGF, may contribute to activation of VEGFR1 in these tumors. Taken together, these results suggest that VEGFR1/PlGF may 
function in the initial relative resistance and subsequent response of NGP tumors to VEGFR2 blockade.

Notchl and Jaggedl are expressed in vasculature of DC101treated NGP tumors. The Notch signaling pathway plays a key role in vascular cell fate determination, and the Notch ligand Dll4 has been shown to play an important role in tumor angiogenesis $(34,35)$. Therefore, we examined expression of Notch receptors and ligands in DC101-treated NGP xenografts. Notch1 is readily detected in the vasculature of control day 0 tumors, and increases 1 day after initiation of VEGFR2 blockade, persisting at day 10 (Fig. 4A). Activated Notch1, using an antibody recognizing the intracellular peptide resulting from ligand-binding and processing of the Notch1 receptor (NotchICN), was detected in the vasculature of DC101-treated tumors (Fig. 4B), but rarely in controls (not shown). Vascular expression of the Notch down-stream target HEY2 also increased after DC101 treatment (data not shown). Jagged1, previously shown to stabilize EC via contacts with perivascular cells $(29,30)$, was also highly expressed in vasculature of NGP controls, and persisted after DC101 (Fig. 4C). NGP control and DC101-treated tumors expressed only scant amounts of Dll4 (Fig. 4C).

\section{Discussion}

Our recent pediatric Phase I trial of the VEGF inhibitor bevacizumab suggests that this approach may be exceptionally well tolerated in childhood (36). Together with the established efficacy of anti-VEGF agents in multiple adult cancers, this finding has increased interest in devising anti-angiogenic strategies for children with treatment-refractory tumors. Advanced stages of $M Y C N$-amplified neuroblastoma, the most common primary abdominal tumor of childhood, have been linked to increased expression of angiogenic mediators including VEGF (6). Thus, understanding the mechanisms supporting vessel survival in neuroblastoma may provide important therapeutic information for affected children.

While we and others have previously shown that antiangiogenic agents can restrict tumor growth in neuroblastoma (37-42), the mechanisms which allow treatmentrefractory neuroblastoma to evade this strategy have not been studied. In the present study, we demonstrated that VEGFR2 blockade only slightly perturbs established $M Y C N$-amplified tumors, with no restriction of tumor growth and lack of vessel disruption. However, increases in both hypoxia and significantly altered expression of a validated hypoxiaresponse metagene were detected, arguing that resistance to this treatment may partly lie in the ability of NB to support vascular survival by rapidly inducing alternative proangiogenic mechanisms.

PlGF has been shown to increase in a number of tumor systems when VEGF signaling is disrupted, and is known to be induced by hypoxia. Similarly, in these experiments we detected progressive increases in expression of PIGF protein in DC101-treated NGP tumors between days 1 and 10 of treatment by ELISA. We also found that expression of its cognate VEGFR1 receptor strikingly increased in NGP tumor vasculature after DC101 treatment. Further, activation of VEGFR1 was also enhanced, as demonstrated by immuno- staining for its phosphorylated form. Collectively, these data suggest that PlGF/VEGFR1 may function in the compensatory response of NGP tumors to loss of VEGF/VEGFR2 signaling.

In our studies, DC101 treatment elicited increased expression of HEY2, a key Notch target in the hypoxiaresponse metagene. We localized expression of HEY2 in NGP tumors to vasculature, finding increased expression after DC101 treatment (data not shown). Further, expression of the Notch 1 receptor rapidly increased 1 day after initiation of VEGFR2 blockade, and confirmed increases of the processed form responsible for activating the Notch signaling cascade in the nucleus (NotchICN) in DC101-treated tumors. We have recently reported that inhibition of Notch signaling by a soluble construct based on the extracellular domain of the Notch1 receptor can increase hypoxia and destabilize vasculature in NGP tumors (43). Collectively, these data support a role for Notch in maintaining vascular integrity in this model, both initially and during the response to VEGFR inhibition.

Differential functions of Notch ligands may also play a role in the stability or rapid adaptation of NGP tumor vasculature to VEGFR2 inhibition. Jagged1 has been shown to function in vessels subjected to injury, and plays a role in vascular stabilization $(29,30)$. Jagged 1 was highly expressed in vasculature of NGP controls, with expression persisting after DC101 treatment. In contrast, both control and DC101-treated xenograft vessels expressed only scant amounts of Dll4. Based on the established role of Jagged1 in promoting vessel integrity, we speculate that the striking expression of this ligand in NGP tumor vessels may confer particular resilience to microenvironmental stress, potentially by interaction with Notch1 receptors rapidly up-regulated during VEGFR2 blockade on adjacent vascular cells.

Our findings indicate that $M Y C N$-amplified neuroblastoma tumors may be relatively resistant to disruption of VEGF/VEGFR2 signaling, and that such resistance may result both from initial, tumor-specific differences in vessels (such as Jagged1 expression) and the ability of this system to respond to hypoxia by inducing alternative proangiogenic mechanisms. One such alternative mechanism may involve activation of the alternative VEGF receptor VEGFR1 by the hypoxia-regulated ligand PIGF. Activation of Notch1 signaling by Jagged1 may also contribute to vessel stability when the VEGF/VEGFR2 pathway is inhibited. Targeting of these alternative mechanisms may provide increased efficacy in treating clinically aggressive childhood neuroblastoma.

\section{Acknowledgements}

The investigators were supported by National Cancer Institute grants 1RO1-CA088951 (D.J.Y), 1R01-CA12464401A2 (D.J.Y.), 1R01-CA100451 (J.J.K.), K08-CA107077 (J.H.), Tay-Bandz, Inc. (D.J.Y.), Pediatric Cancer Foundation (J.J.K., D.J.Y.), and the Children's Neuroblastoma Cancer Foundation (S.L.H.). We thank Zev Noah Kornfield, Judy Tsai and Lucy Eljuga for technical assistance.

\section{References}

1. Weidner N, Semple JP, Welch WR and Folkman J: Tumor angiogenesis and metastasis - correlation in invasive breast carcinoma. N Engl J Med 324: 1-8, 1991. 
2. Weidner N, Carroll PR, Flax J, Blumenfeld W and Folkman J: Tumor angiogenesis correlates with metastasis in invasive prostate carcinoma. Am J Pathol 143: 401-409, 1993.

3. Beecken WD, Fernandez A, Joussen AM, Achilles EG, Flynn E, Lo KM, Gillies SD, Javaherian K, Folkman J and Shing Y: Effect of antiangiogenic therapy on slowly growing, poorly vascularized tumors in mice. J Natl Cancer Inst 93: 382-387, 2001.

4. Maeda K, Chung YS, Takatsuka S, Ogawa Y, Sawada T, Yamashita Y, Onoda N, Kato Y, Nitta A, Arimoto Y, et al: Tumor angiogenesis as a predictor of recurrence in gastric carcinoma. J Clin Oncol 13: 477-481, 1995.

5. Horak ER, Leek R, Klenk N, LeJeune S, Smith K, Stuart N, Greenall M, Stepniewska K and Harris AL: Angiogenesis, assessed by platelet/endothelial cell adhesion molecule antibodies, as indicator of node metastases and survival in breast cancer. Lancet 340: 1120-1124, 1992.

6. Eggert A, Ikegaki N, Kwiatkowski J, Zhao H, Brodeur GM and Himelstein BP: High-level expression of angiogenic factors is associated with advanced tumor stage in human neuroblastomas. Clin Cancer Res 6: 1900-1908, 2000

7. de Vries C, Escobedo JA, Ueno H, Houck K, Ferrara N and Williams LT: The fms-like tyrosine kinase, a receptor for vascular endothelial growth factor. Science 255: 989-991, 1992.

8. Grosskreutz CL, Anand-Apte B, Duplaa C, Quinn TP, Terman BI, Zetter B and D'Amore PA: Vascular endothelial growth factorinduced migration of vascular smooth muscle cells in vitro. Microvasc Res 58: 128-136, 1999.

9. Soker S, Takashima S, Miao HQ, Neufeld G and Klagsbrun M: Neuropilin-1 is expressed by endothelial and tumor cells as an isoform-specific receptor for vascular endothelial growth factor Cell 92: 735-745, 1998

10. Yang JC, Haworth L, Steinberg SM, Rosenberg SA and Novotny W: A randomized double-blind placebo-controlled trial of Bevacizumab (anti-VEGF antibody) demonstrating a prolongation in time to progression in patients with metastatic renal cancer. Proc ASCO 21: 5a, 2002.

11. Kabbinavar F, Hurwitz HI, Fehrenbacher L, Meropol NJ Novotny WF, Lieberman G, Griffing $S$ and Bergsland E: Phase II, randomized trial comparing bevacizumab plus fluorouracil (FU)/leucovorin (LV) with FU/LV alone in patients with metastatic colorectal cancer. J Clin Oncol 21: 60-65, 2003 .

12. Hurwitz H, Fehrenbacher L, Novotny W, Cartwright T, Hainsworth J, Heim W, Berlin J, Baron A, Griffing S, Holmgren E, Ferrara N, Fyfe G, Rogers B, Ross R and Kabbinavar F: Bevacizumab plus irinotecan, fluorouracil, and leucovorin for metastatic colorectal cancer. N Engl J Med 350: 2335-2342, 2004.

13. Casanovas O, Hicklin DJ, Bergers G and Hanahan D: Drug resistance by evasion of antiangiogenic targeting of VEGF signaling in late-stage pancreatic islet tumors. Cancer Cell 8: 299-309, 2005.

14. Winkler F, Kozin SV, Tong RT, Chae SS, Booth MF, Garkavtsev I, Xu L, Hicklin DJ, Fukumura D, di Tomaso E, Munn LL and Jain RK: Kinetics of vascular normalization by VEGFR2 blockade governs brain tumor response to radiation: role of oxygenation, angiopoietin-1, and matrix metalloproteinases. Cancer Cell 6: 553-563, 2004.

15. Huang J, Frischer JS, New T, Kim ES, Serur A, Lee A, Kadenhe-Chiwishe A, Pollyea DA, Yokoi A, Holash J, Yancopoulos GD, Kandel JJ and Yamashiro DJ: TNP-470 promotes initial vascular sprouting in xenograft tumors. Mol Cancer Ther 3: 335-343, 2004.

16. Willett CG, Boucher Y, Duda DG, di Tomaso E, Munn LL, Tong RT, Kozin SV, Petit L, Jain RK, Chung DC, Sahani DV, Kalva SP, Cohen KS, Scadden DT, Fischman AJ, Clark JW, Ryan DP, Zhu AX, Blaszkowsky LS, Shellito PC, MinoKenudson $M$ and Lauwers GY: Surrogate markers for antiangiogenic therapy and dose-limiting toxicities for bevacizumab with radiation and chemotherapy: continued experience of a phase I trial in rectal cancer patients. J Clin Oncol 23: 8136-8139, 2005.

17. Fong GH, Rossant J, Gertsenstein M and Breitman ML: Role of the Flt-1 receptor tyrosine kinase in regulating the assembly of vascular endothelium. Nature 376: 66-70, 1995.

18. Hiratsuka S, Maru Y, Okada A, Seiki M, Noda T and Shibuya M: Involvement of Flt-1 tyrosine kinase (vascular endothelial growth factor receptor-1) in pathological angiogenesis. Cancer Res 61: 1207-1213, 2001.
19. Witmer AN, Dai J, Weich HA, Vrensen GF and Schlingemann RO: Expression of vascular endothelial growth factor receptors 1 , 2 , and 3 in quiescent endothelia. J Histochem Cytochem 50: 767-777, 2002.

20. Morowitz MJ, Barr R, Wang Q, King R, Rhodin N, Pawel B, Zhao H, Erickson SA, Sheppard GS, Wang J, Maris JM and Shusterman S: Methionine aminopeptidase 2 inhibition is an effective treatment strategy for neuroblastoma in preclinical models. Clin Cancer Res 11: 2680-2685, 2005.

21. Carmeliet P, Moons L, Luttun A, Vincenti V, Compernolle V, De Mol M, Wu Y, Bono F, Devy L, Beck H, Scholz D, Acker T, DiPalma T, Dewerchin M, Noel A, Stalmans I, Barra A, Blacher S, Vandendriessche T, Ponten A, Eriksson U, Plate KH, Foidart JM, Schaper W, Charnock-Jones DS, Hicklin DJ, Herbert JM, Collen D and Persico MG: Synergism between vascular endothelial growth factor and placental growth factor contributes to angiogenesis and plasma extravasation in pathological conditions. Nat Med 7: 575-583, 2001.

22. Matsumoto K, Suzuki K, Koike H, Okamura K, Tsuchiya K, Uchida T, Takezawa Y, Kobayashi M and Yamanaka H: Prognostic significance of plasma placental growth factor levels in renal cell cancer: an association with clinical characteristics and vascular endothelial growth factor levels. Anticancer Res 23: 4953-4958, 2003.

23. Parr C, Watkins G, Boulton M, Cai J and Jiang WG: Placenta growth factor is over-expressed and has prognostic value in human breast cancer. Eur J Cancer 41: 2819-2827, 2005.

24. Zhang L, Chen J, Ke Y, Mansel RE and Jiang WG: Expression of Placenta growth factor (PlGF) in non-small cell lung cancer (NSCLC) and the clinical and prognostic significance. World J Surg Oncol 3: 68, 2005.

25. Wei SC, Tsao PN, Yu SC, Shun CT, Tsai-Wu JJ, Wu CH, Su YN, Hsieh FJ and Wong JM: Placenta growth factor expression is correlated with survival of patients with colorectal cancer. Gut 54: 666-672, 2005.

26. Gerber HP, Kowalski J, Sherman D, Eberhard DA and Ferrara N: Complete inhibition of rhabdomyosarcoma xenograft growth and neovascularization requires blockade of both tumor and host vascular endothelial growth factor. Cancer Res 60: 6253-6258, 2000.

27. Paris D, Quadros A, Patel N, DelleDonne A, Humphrey J and Mullan M: Inhibition of angiogenesis and tumor growth by beta and gamma-secretase inhibitors. Eur J Pharmacol 514: 1-15, 2005.

28. Zeng Q, Li S, Chepeha DB, Giordano TJ, Li J, Zhang H, Polverini PJ, Nor J, Kitajewski J and Wang CY: Crosstalk between tumor and endothelial cells promotes tumor angiogenesis by MAPK activation of Notch signaling. Cancer Cell 8: $13-23,2005$.

29. Xue Y, Gao X, Lindsell CE, Norton CR, Chang B, Hicks C, Gendron-Maguire M, Rand EB, Weinmaster G and Gridley T: Embryonic lethality and vascular defects in mice lacking the Notch ligand Jagged1. Hum Mol Genet 8: 723-730, 1999.

30. Lindner V, Booth C, Prudovsky I, Small D, Maciag T and Liaw L: Members of the Jagged/Notch gene families are expressed in injured arteries and regulate cell phenotype via alterations in cell matrix and cell-cell interaction. Am J Pathol 159: 875-883, 2001 .

31. Subramanian A, Tamayo P, Mootha VK, Mukherjee S, Ebert BL, Gillette MA, Paulovich A, Pomeroy SL, Golub TR, Lander ES and Mesirov JP: Gene set enrichment analysis: a knowledgebased approach for interpreting genome-wide expression profiles. Proc Natl Acad Sci USA 102: 15545-15550, 2005.

32. Winter SC, Buffa FM, Silva P, Miller C, Valentine HR, Turley H, Shah KA, Cox GJ, Corbridge RJ, Homer JJ, Musgrove B, Slevin N, Sloan P, Price P, West CM and Harris AL: Relation of a hypoxia metagene derived from head and neck cancer to prognosis of multiple cancers. Cancer Res 67: 3441-3449, 2007.

33. Witte L, Hicklin DJ, Zhu Z, Pytowski B, Kotanides H, Rockwell $\mathrm{P}$ and Bohlen P: Monoclonal antibodies targeting the VEGF receptor-2 (Flk1/KDR) as an anti-angiogenic therapeutic strategy. Cancer Metastasis Rev 17: 155-161, 1998.

34. Noguera-Troise I, Daly C, Papadopoulos NJ, Coetzee S, Boland P, Gale NW, Lin HC, Yancopoulos GD and Thurston G: Blockade of Dll4 inhibits tumour growth by promoting non-productive angiogenesis. Nature 444: 1032-1037, 2006.

35. Ridgway J, Zhang G, Wu Y, Stawicki S, Liang WC, Chanthery Y, Kowalski J, Watts RJ, Callahan C, Kasman I, Singh M, Chien M, Tan C, Hongo JA, de Sauvage F, Plowman G and Yan M: Inhibition of D114 signalling inhibits tumour growth by deregulating angiogenesis. Nature 444: 1083-1087, 2006. 
36. Bender JL, Adamson PC, Reid JM, Xu L, Baruchel S, Shaked Y, Kerbel RS, Cooney-Qualter EM, Stempak D, Chen HX Nelson MD, Krailo MD, Ingle AM, Blaney SM, Kandel JJ and Yamashiro DJ: Phase I trial and pharmacokinetic study of bevacizumab in pediatric patients with refractory solid tumors: a Children's Oncology Group Study. J Clin Oncol 26: 399-405, 2008.

37. Katzenstein HM, Salwen HR, Nguyen NN, Meitar D and Cohn SL: Antiangiogenic therapy inhibits human neuroblastoma growth. Med Pediatr Oncol 36: 190-193, 2001.

38. Kim ES, Serur A, Huang J, Manley CA, McCrudden KW, Frischer JS, Soffer SZ, Ring L, New T, Zabski S, Rudge JS, Holash J, Yancopoulos GD, Kandel JJ and Yamashiro DJ: Potent VEGF blockade causes regression of coopted vessels in a model of neuroblastoma. Proc Natl Acad Sci USA 99: 11399-11404, 2002.

39. Kaicker S, McCrudden KW, Beck L, New T, Huang J, Frischer JS, Serur A, Kadenhe-Chiweshe A, Yokoi A, Kandel JJ and Yamashiro DJ: Thalidomide is anti-angiogenic in a xenograft model of neuroblastoma. Int J Oncol 23: 1651-1655, 2003 .
40. Streck CJ, Zhang Y, Miyamoto R, Zhou J, Ng CY, Nathwani AC and Davidoff AM: Restriction of neuroblastoma angiogenesis and growth by interferon-alpha/beta. Surgery 136: 183-189, 2004.

41. Segerstrom L, Fuchs D, Backman U, Holmquist K, Christofferson R and Azarbayjani F: The anti-VEGF antibody bevacizumab potently reduces the growth rate of high-risk neuroblastoma xenografts. Pediatr Res 60: 576-581, 2006.

42. Hamner JB, Dickson PV, Sims TL, Zhou J, Spence Y, Ng CY and Davidoff AM: Bortezomib inhibits angiogenesis and reduces tumor burden in a murine model of neuroblastoma. Surgery 142: 185-191, 2007.

43. Funahashi Y, Hernandez SL, Das I, Ahn A, Huang J, Vorontchikhina M, Sharma A, Kanamaru E, Borisenko V, Desilva DM, Suzuki A, Wang X, Shawber CJ, Kandel JJ, Yamashiro DJ and Kitajewski J: A notch1 ectodomain construct inhibits endothelial notch signaling, tumor growth, and angiogenesis. Cancer Res 68: 4727-4735, 2008. 